\title{
The Relationship Between Smoking and Gastric
}

\section{Histopathology in Patients Presented to the}

\section{Emergency Department with Dyspeptic Complaints and Underwent Endoscopic Examination}

\author{
Mehmet Ali Bilgili \\ Van Training and Research Hospital, Department of Emergency, Van, Turkey
}

\begin{abstract}
Smoking is responsible for the etiology of most malignancies. It also causes pathologies involving the gastrointestinal system (GIS) such as gastroesophageal reflux (GER), peptic ulcer (PU), and malignancy. In our study, we aimed to examine the relationship of histopathological findings and the presence of helicobacter pylori (HP) with smoking in patients, who presented to the emergency department with dyspeptic complaints.

A total of 118 patients, who underwent upper GIS endoscopy were included in the study. The patients were grouped as non-smokers, smokers, and ex-smokers. Data on demographic characteristics, smoking habits, alcohol use, endoscopic and histopathological findings were documented. In addition to smoking, the relationship between the number of cigarettes smoked and the time of cessation with HP and histopathological findings were examined.

A total of 118 patients, $60(50.8 \%)$ female and $58(49.2 \%)$ male, were included in the study. There were 76 non-smokers, 31 smokers, 11 ex-smokers. The presence of HP and intestinal metaplasia were significantly higher in the group of smokers. The presence of HP and intestinal metaplasia were higher in smokers of 10 years or more compared to the non-smokers. Those who had quit smoking for less than 10 years had a higher rate of the presence of HP and metaplasia compared to the non-smokers.

The fact that various histopathological data can be improved by preventing smoking, which is a serious public health problem, highlights the importance of raising awareness on this issue.
\end{abstract}

Keywords: Emergency department, dyspepsia, smoking, helicobacter pylori; metaplasia, inflammation

\section{Introduction}

Smoking is one of the most common carcinogenic substances. Despite this fact, it is one of the most commonly used addictive substances in the world. Consumption of tobacco and tobacco products is quite common in our country as well as in the whole world. Although the number of addicts has decreased from 30 million to 20 million with the studies conducted in recent years, the rate of smoking is still around $25-30 \%$ (1).

Smoking is found to be responsible for the etiology of most malignancies, particularly lung, larynx, bladder, stomach, and colon malignancies (2-5). In addition, smoking is one of the etiological reasons for many chronic diseases and health issues that are difficult to treat, such as atherosclerosis, coronary artery disease (CAD), cerebrovascular diseases (CVD), chronic obstructive pulmonary disease (COPD), intestinal ischemic diseases, and Buerger's disease (5-8). Smoking has many systemic effects. The most prominent effects of smoking on the gastrointestinal system are dental caries, bad breath, poor oral hygiene, dyspepsia, gastroesophageal reflux, peptic ulcer, increased motility, and diarrhea (5-9). Smoking has been found to be associated with frequent exacerbations and poor response to treatment in inflammatory bowel diseases $(10,11)$. In addition, smoking is a serious factor in the development of malignancies involving many gastrointestinal systems (GIS) such as the esophagus, stomach, colon, liver, and pancreas (2-9).

In a previous study conducted on the effects of smoking on GIS, it was stated to have a suppressive effect on intestinal microbiota; and therefore it was associated with frequent diarrhea and gastroenteritis (12). In another study investigating the effect of smoking and alcohol consumption on GIS; it was 
reported that smoking decreased lower esophageal sphincter pressure, increased reflux, decreased the release of bicarbonate secreted in the esophageal mucosa, and neutralized stomach acid. Therefore, it was reported to increase the frequency of gastroesophageal reflux, the frequency of esophagitis due to reflux, and Barrett metaplasia; and secondary to this, esophageal adenocarcinoma was reported to increase (13). In our study, we aimed to examine the relationship of the presence of helicobacter pylori (HP) and histopathological examination with smoking in patients, who presented to the emergency service with dyspeptic complaints and underwent an upper GI endoscopy.

\section{Materials and Methods}

Study Design: A total of 118 patients, who presented to the emergency unit of our hospital with dyspeptic complaints and underwent upper gastrointestinal system (GIS) endoscopy, were included in the study. Our study had a retrospective research design. The patients, who were pregnant, who underwent organ transplantation (liver, kidney, bone marrow), who had chronic liver and chronic kidney diseases, and who had an operation related to GIS, were excluded from the study.Demographic characteristics (age, gender), anthropometric measurements (height, weight, body mass index (BMI)), smoking habits (number of cigarettes smoked and duration of smoking, smoking cessation period), and alcohol consumption habits of the patients were inquired. In addition, the data regarding the histopathological findings and the presence of helicobacter pylori (HP) were documented in the pathological examination performed with endoscopy.

Endoscopic Evaluation: Endoscopic findings and histopathological data of the patients were documented. The endoscopy was performed by using the Fujinon EG530WR endoscopy device in the endoscopy unit of our hospital. All patients fasted for 6 hours before the endoscopy. After the local pharyngeal xylocaine anesthesia, the endoscopy procedure was performed. The stomach and duodenum were examined in detail during the endoscopy, and biopsies were taken for helicobacter pylori infection. Endoscopic findings were compared between the groups of smokers, ex-smokers, and non-smokers.

Tissue Biopsy and Histopathological Evaluation: A punch biopsy was taken using biopsy forceps from the antrum of the patients, who underwent endoscopic evaluation. The biopsy materials were sent to the pathology laboratory in $10 \%$ formaldehyde. Following the routine tissue monitoring procedures, paraffin-embedded tissue samples were cut at 5-micron thickness, stained with routine Giemsa, and evaluated under a light microscope. Samples without the required competence for evaluation were excluded from the study. The materials taken were evaluated by three different experienced pathologists without disclosing clinical information. The tissue was evaluated in terms of the presence of HP.

Ethical Statement: Ethical approval for this study was obtained from the Ethics Committee of our hospital. All procedures were carried out in accordance with the ethical standards of the human experiment committee of our institution as well as the Helsinki Declaration. Written informed consent forms were obtained from all participants in the study.

Statistical Analysis: Descriptive statistics for the continuous variables were presented as Mean, Standard deviation, minimum and maximum values while count and percentages for categorical variables. Data were tested for normal distribution using the Kolmogorov-Smirnov test, histogram, and \pm sd. Oneway ANOVA was used to compare group means. Duncan multiple comparison test was also used to identify different group means followed by ANOVA. In addition, chi-square test was performed to determine the relationship between categorical variables. Statistical significance level was considered as $5 \%$ and The Statistical Package for the Social Sciences 19.0 (SPSS Armonk, NY: IBM Corp.)" was used for all statistical computations.

\section{Results}

A total of 118 patients, $60(50.8 \%)$ female and 58 $(49.2 \%)$ male, who underwent endoscopic examination due to dyspeptic complaints were included in the study. Of these patients, 11 had quit smoking, 31 were still smokers, and the remaining 76 did not smoke. Demographic data, height, weight, BMI, and histopathological findings were compared among all three groups. As a result of the comparisons, the rate of smoking was statistically significantly higher in male patients $(\mathrm{p}=0.001)$. There was no significant difference between the groups in terms of age, weight, and BMI ( $p>0.05)$. The mean height of smokers was greater in the group of smokers $(p=0.005)$. This was believed to be due to the fact that the smokers were mostly male. In addition, the presence of HP $(p=0.035)$ and intestinal metaplasia $(\mathrm{p}=0.037)$ were significantly higher in the group of smokers. There was no 
Table 1. The relationship of smoking with the presence of helicobacter pylori and histopathological features

\begin{tabular}{lcccc}
\hline & Non-smokers & Ex-smokers & Smokers & \\
\hline & Mean \pm St. Dev & Mean \pm St. Dev & Mean \pm St. Dev & $\mathrm{p}$ \\
\hline Age (years) & $35.8 \pm 12.7$ & $42.4 \pm 12.8$ & $38.2 \pm 11.2$ & 0.215 \\
Height $(\mathrm{cm})$ & $163.1 \pm 8.8 \mathrm{~b} \#$ & $170.2 \pm 6.6 \mathrm{a}$ & $168.7 \pm 11.2 \mathrm{a}$ & 0.003 \\
Weight $(\mathrm{kg})$ & $66.5 \pm 11.6$ & $71.3 \pm 7.1$ & $68.9 \pm 11.8$ & 0.312 \\
BMI $(\mathrm{kg} / \mathrm{m} 2)$ & $24.8 \pm 4.2$ & $24.3 \pm 1.7$ & $24.2 \pm 3.7$ & 0.712 \\
& $\mathrm{n}(\%)$ & $\mathrm{n}(\%)$ & $\mathrm{n}(\%)$ & \\
Gender (Female) & $49(64.5 \%) \mathrm{a}$ & $2(18.2 \%) \mathrm{c}$ & $12(34.3 \%) \mathrm{b}$ & 0.001 \\
Presence of HP (present) & $40(52.6 \%) \mathrm{c}$ & $8(72.7 \%) \mathrm{b}$ & $27(77.1 \%) \mathrm{a}$ & 0.035 \\
Intestinal metaplasia (present) & $9(11.8 \%) \mathrm{b}$ & $3(27.3 \%) \mathrm{a}$ & $11(31.4 \%) \mathrm{a}$ & 0.037 \\
Chronic inflammation (severe) & $8(10.5 \%)$ & $3(27.3 \%)$ & $7(20.0 \%)$ & 0.200 \\
Atrophy (present) & $3(3.9 \%)$ & $0(0 \%)$ & $1(2.9 \%)$ & 0.779 \\
\hline
\end{tabular}

\#: Different lower cases in the same row represent statistically significant differences among the groups $(\mathrm{p}<0.05)$

Table 2. The relationship of the number of cigarettes smoked with the presence of helicobacter pylori and histopathological features

\begin{tabular}{lcccc}
\hline & Non-smokers & $<10$ packs/year & $\geq 10$ packs/year & \\
\hline & Mean \pm St. Dev & Mean \pm St. Dev & Mean \pm St. Dev & $\mathrm{p}$ \\
\hline Age (years) & $35.8 \pm 12.7 \mathrm{~b} \#$ & $32.8 \pm 10.1 \mathrm{~b}$ & $42.7 \pm 10.2 \mathrm{a}$ & 0.031 \\
Height $(\mathrm{cm})$ & $163.1 \pm 8.8 \mathrm{~b}$ & $166.2 \pm 13.8 \mathrm{a}$ & $170.1 \pm 8.5 \mathrm{a}$ & 0.002 \\
Weight $(\mathrm{kg})$ & $66.5 \pm 11.6$ & $66.6 \pm 11.1$ & $70.8 \pm 12.3$ & 0.156 \\
BMI (kg/m2) & $24.8 \pm 4.2$ & $24.1 \pm 4.7$ & $24.3 \pm 2.8$ & 0.593 \\
& $\mathrm{n}(\%)$ & $\mathrm{n}(\%)$ & $\mathrm{n}(\%)$ & \\
Gender (Female) & $49(64.5 \%) \mathrm{a}$ & $7(43.8 \%) \mathrm{b}$ & $5(26.3 \%) \mathrm{c}$ & 0.003 \\
Presence of HP (present) & $40(52.6 \%) \mathrm{c}$ & $11(68.8 \%) \mathrm{b}$ & $16(84.2 \%) \mathrm{a}$ & 0.012 \\
Intestinal metaplasia (present) & $9(11.8 \%) \mathrm{b}$ & $4(25.0 \%) \mathrm{ab}$ & $7(36.8 \%) \mathrm{a}$ & 0.009 \\
Chronic inflammation (severe) & $8(10.5 \%)$ & $4(25.0 \%)$ & $3(15.8 \%)$ & 0.521 \\
Atrophy (present) & $3(3.9 \%)$ & $0(0 \%)$ & $1(5.3 \%)$ & 0.798 \\
\hline
\end{tabular}

\#: Different lower cases in the same row represent statistically significant differences among the groups $(\mathrm{p}<0.05)$

difference between the groups in terms of the presence of inflammation and atrophy histopathologically ( $\mathrm{p}>0.05)$ (Table-1).

When non-smokers and the patients, who had been smoking for less than 10 years, were compared, no significant difference was found between the groups ( $>>0.05)$. However, when non-smokers and the patients, who had been smoking for 10 years or more, were compared, the presence of HP (0.012) and intestinal metaplasia $(p=0.009)$ were higher in the group, who had been smoking for 10 years or more, at a statistically significant level. In addition, male patients were the majority, the mean height was greater, and the mean age was higher in the group, who had been smoking for 10 years or more $(\mathrm{p}$ $<0.05)$ (Table-2).

When the groups of non-smokers and ex-smokers were compared, the presence of HP $(p=0.024)$ and intestinal metaplasia $(p=0.031$ ) were found to be statistically higher in patients, who had quit smoking for less than 10 years. Other parameters were similar in both groups. When the non-smokers group was compared with the groups that had quit smoking for 10 years or more, there was no significant difference in terms of the histopathological findings (Table-3).

\section{Discussion}

It is known that tobacco consumption causes serious changes in the GIS by inhibiting many protective mechanisms, triggering mechanisms that lead to inflammation, and making significant changes in the intestinal microbiota $(11,13)$. Studies have shown that smoking, which is the most common form of tobacco consumption, increases the frequency of reflux esophagitis and peptic ulcer $(7,10,13-15)$. There are also studies demonstrating that smoking increases intestinal inflammation, and is therefore associated with both its etiology and activation of the disease in inflammatory bowel diseases (9-11). In addition, it has 
Table 3. The relationship of smoking cessation time with the presence of helicobacter pylori and histopathological features

\begin{tabular}{lcccc}
\hline & Non-smokers & $<10$ years & $\geq 10$ years & \\
\hline & Mean \pm St. Dev & Mean \pm St. Dev & Mean \pm St. Dev & $\mathrm{p}$ \\
\hline Age (years) & $35.8 \pm 12.7 \mathrm{~b} \#$ & $36.5 \pm 7.9 \mathrm{~b}$ & $49.6 \pm 14.6 \mathrm{a}$ & 0.023 \\
Height $(\mathrm{cm})$ & $163.1 \pm 8.8 \mathrm{~b}$ & $169.6 \pm 8.7 \mathrm{a}$ & $171.8 \pm 3.4 \mathrm{a}$ & 0.034 \\
Weight $(\mathrm{kg})$ & $66.5 \pm 11.6$ & $68.8 \pm 7.7$ & $74.4 \pm 5.5$ & 0.139 \\
BMI $(\mathrm{kg} / \mathrm{m} 2)$ & $24.8 \pm 4.2$ & $23.8 \pm 2.1$ & $25.0 \pm 2.3$ & 0.949 \\
& $\mathrm{n}(\%)$ & $\mathrm{n}(\%)$ & $\mathrm{n}(\%)$ & \\
Gender (Female) & $49(64.5 \%) \mathrm{a}$ & $2(33.3 \%) \mathrm{b}$ & $0(0 \%) \mathrm{c}$ & 0.004 \\
Presence of HP (present) & $40(52.6 \%)$ & $6(100 \%)$ & $0(40.0 \%)$ & 0.584 \\
Intestinal metaplasia (present) & $9(11.8 \%)$ & $3(50.0 \%)$ & $0(0 \%)$ & 0.414 \\
Chronic inflammation (present) & $8(10.5 \%)$ & $2(33.3 \%)$ & $1(20.0 \%)$ & 0.514 \\
Atrophy (present) & $3(3.9 \%)$ & $0(0 \%)$ & $0(0 \%)$ & 0.651 \\
\hline
\end{tabular}

\#: Different lower cases in the same row represent statistically significant differences among the groups $(\mathrm{p}<0.05)$

been reported that smoking has a negative effect on intestinal microbiota, and it is associated with frequent intestinal infections (12).

In a study examining smoking-related cases of cancer and mortality in China on a large patient population, it was found that smoking was the cause of many cancers, the course of the malignancies that developed in smokers was more mortal, the mortality rates increased gradually in the years 2005, 2010, and 2015 , the most common malignancies were found in the lung, liver, esophagus, and stomach, and mortality was mostly caused by these malignancies. They stated that this required a serious measure regarding smoking (15). Yang et al. conducted a similar study in Asian countries including China, Japan, India, Singapore, Korea, and Taiwan. As a result, they mentioned that smoking was intense and increasing in Asian countries, smoking-related chronic diseases and malignancies increased, smoking-related mortality had also increased, creating a serious public health problem, and that much more serious consequences would be encountered in the future if necessary measures were not taken. (14).

Although many mechanisms play a role in the development of GIS malignancy in smokers, it has been reported that smoking increases the presence of HP. In addition, the development of malignancy accelerates with the effect of HP (16-19). In a study they conducted on gastric carcinogenesis, the presence of HP and antioxidant systems, Toh et al. found that smoking suppresses antioxidant systems with its hypoxic effect, causes the secretion of reactive oxygen radicals, and is also associated with the presence of HP. They stated that this was closely related to gastric carcinogenesis (4). In studies conducted on the relationship between smoking and the presence of HP and the relationship between smoking and peptic ulcer, the presence of HP and peptic ulcer have been found to be closely associated with smoking. Komar et al. described smoking as an important risk factor for gastric and duodenal ulcers (20). In two different studies on the endoscopic findings of smoking and the consumption of other substances, smoking was found to be closely associated with the increase in dyspeptic complaints, HP infection and the frequency of peptic ulcer (21, 22). Lee et al. defined smoking as a risk factor for peptic ulcer, and stated that smoking was also responsible for poor response to treatment (23). In addition, in molecular analysis of GIS diseases conducted by Li et al., smoking was described as the trigger of most of the mechanisms, thereby causing inflammation, metaplasia, the presence of HP, peptic ulcer and gastric carcinoma at a molecular level (24). In our study, the presence of HP and intestinal metaplasia were observed with a higher rate in the group of smokers. In addition, the presence of HP and intestinal metaplasia were found to be statistically higher in patients, who had quit smoking for less than 10 years, compared to the non-smokers. However, the presence of HP and intestinal metaplasia in patients, who had quit smoking for 10 years or more, were similar compared to the non-smokers group. This indicates that smoking increases the presence of HP and is associated with intestinal metaplasia, quitting smoking for 10 years or more contributes to the regression of intestinal metaplasia or at least does not progress to intestinal metaplasia. In the light of these data, it can be argued indirectly that smoking triggers the two mechanisms, which play a role in gastric carcinogenesis; and therefore, it is responsible for the development of gastric cancer.

Our study had both strengths and limitations. The number of patients was low, and the study was 
conducted according to the statement of the patients, which were the limitations of our study. However, documenting detailed demographic and histopathological data of all patients and basing them on objective data, and examining the relationship between the amount of cigarettes smoked, the time of cassation and histopathology were the strengths of our study.

As a result, smoking is listed in the etiology of many diseases. In parallel with this, most GIS symptoms and signs are more common in smokers. The major signs and symptoms are reflux esophagitis, peptic ulcer, development of intestinal metaplasia and increase in the presence of HP. In addition, it is important that the harmful effects on GIS increase with the amount of cigarettes smoked, and that GIS findings exhibit similar characteristics to non-smokers after a certain period of smoking cessation. The fact that various histopathological data can be improved by preventing smoking, which is a serious public health problem, highlights the importance of raising awareness on this issue.

\section{References}

1. Sahan C, Gunay T, Simsek H, Soysal A, Ergor G. Socioeconomic factors associated with tobacco smoking in Turkey: a crosssectional, population-based study. East Mediterr Health J 2018; 24: 705-713.

2. Roh S. Scientific Evidence for the Addictiveness of Tobacco and Smoking Cessation in Tobacco Litigation. J Prev Med Public Health 2018; 51: 1-5.

3. Xu X, Bishop EE, Kennedy SM, Simpson SA, Pechacek TF. Annual healthcare spending attributable to cigarette smoking: an update. Am J Prev Med 2015; 48: 326-333.

4. Wang TW, Asman K, Gentzke AS. et al. Tobacco Product Use Among Adults - United States, 2017. MMWR Morb Mortal Wkly Rep 2018; 67: 1225-1232.

5. Toh JWT, Wilson RB. Pathways of Gastric Carcinogenesis, Helicobacter pylori Virulence and Interactions with Antioxidant Systems, Vitamin $\mathrm{C}$ and Phytochemicals. Int J Mol Sci 2020; 21: 6451

6. Klebe S, Leigh J, Henderson DW, Nurminen M. Asbestos, Smoking and Lung Cancer: An Update. Int J Environ Res Public Health 2019; 17: 258.

7. Scharrer S, Lissner D, Primas C, et al. Passive Smoking Increases the Risk for Intestinal Surgeries in Patients With Crohn's Disease. Inflamm Bowel Dis 2020; 117: 25 .
8. Ramôa CP, Eissenberg T, Sahingur SE. Increasing popularity of waterpipe tobacco smoking and electronic cigarette use: Implications for oral healthcare. J Periodontal Res 2017; 52: 813-823.

9. Naqvi HA, Bilal M, Yousuf S. Ischemic Colitis in Buerger's Disease: Case Presentation and Review. Cureus 2020; 12: 8303.

10. Marín-Jiménez I, Gomollón F. Year 1983: Smoking decreases the risk of ulcerative colitis.Gastroenterol Hepatol 2020; 43: 373 374.

11. Papoutsopoulou S, Satsangi J, Campbell BJ, Probert CS. Review article: impact of cigarette smoking on intestinal inflammationdirect and indirect mechanisms. Aliment Pharmacol Ther 2020; 51: 1268-1285.

12. Harakeh S, Angelakis E, Karamitros T, et al. Impact of smoking cessation, coffee and bread consumption on the intestinal microbial composition among Saudis: A cross-sectional study. PLoS One 2020; 15: 0230895.

13. Ness-Jensen E, Lagergren J. Tobacco smoking, alcohol consumption and gastro-oesophageal reflux disease. Best Pract Res Clin Gastroenterol 2017; 31: 501-508.

14. Yang JJ, Yu D, Wen W, et al. Tobacco Smoking and Mortality in Asia: A Pooled Meta-analysis. JAMA Netw Open 2019; 2: 191474.

15. Xu Z, Qi F, Wang Y, et al. Cancer mortality attributable to cigarette smoking in 2005, 2010 and 2015 in Qingdao, China. PLoS One 2018; 13: 0204221.

16. Konur S, Surmeli N, Bilgili MA, Dertli R, Kayar Y. Is There a Relationship Between Helicobacter Pylori Eradication and Blood Group? Eastern Journal of Medicine 2020; 25: 422-426.

17. Konur S, Kayar Y, Dertli R, Ozkahraman A, Bilgili MA, İliklerden UH. Helikobakter Pilori Enfeksiyonu ve Kan Grubu Arasındaki İlişki. Van Tip Dergisi 2020; 27: 514-519.

18. Agin M, Kayar Y, Dertli R, Konur S, Bilgili MA. The Relationship Between Helicobacter Pylori and Reflux Esophagitis in Children. Van Medical Journal 2020; 27: 184-189.

19. Sahin O, Yesil A, Senates E, et al. Synbiotic therapy increases eradication rate in Helicobacter pylori eradication. Acta Medica 2013; 29: 569.

20. Komar OM, Kizlova NM, Trylevych OD, Kravchenko VV. Risk factors for adverse course of gastric and duodenal peptic ulcer. Wiad Lek 2018; 71: 160-164.

21. Chuang YS, Wu MC, Wang YK, et al. Risks of substance uses, alcohol flush response, Helicobacter pylori infection and upper digestive tract diseases-An endoscopy cross- 
sectional study. Kaohsiung J Med Sci 2019; 35: 341-349.

22. Aro P, Ronkainen J, Storskrubb T, et al. Use of tobacco products and gastrointestinal morbidity: an endoscopic population-based study (the Kalixanda study). Eur J Epidemiol 2010; 25: 741-750.

23. Lee SW, Chang CS, Lee TY, Yeh HZ, Tung CF, Peng YC. Risk factors and therapeutic response in Chinese patients
with peptic ulcer disease. World Gastroenterol 2010; 16: 2017-2022.

24. Li LF, Chan RL, Lu L, Shen J, Zhang L, Wu WK. Cigarette smoking and gastrointestinal diseases: the causal relationship and underlying molecular mechanisms (review). Int J Mol Med 2014; 34: 372-380. 